\title{
Bagaimana Gaya Hidup mempengaruhi Keputusan Pembelian Tiket Online?
}

\author{
Muhammad Ashoer ${ }^{1 *}$, Haerdiansyah Syahnur ${ }^{1}$, Imaduddin Murdifin ${ }^{1}$ \\ ${ }^{1}$ Fakultas Ekonomi, Universitas Muslim Indonesia \\ Jl. Urip Sumoharjo, KM 5.Gedung Fakultas Ekonomi Dan Bisnis, Kampus II UMI \\ Makassar, Sulawesi Selatan, Indonesia \\ "Email:muhammad.ashur@umi.ac.id
}

\begin{abstract}
\begin{tabular}{c} 
Artikel Info \\
\hline Received: \\
6 Desember 2018 \\
Revised: \\
15 Maret 2019 \\
Accepted: \\
30 Maret 2019 \\
\hline
\end{tabular}
ABSTRAK

Abstrak. Bercermin pada gaya hidup dan fenomena pergeseran perilaku netizen pada platform e-commerce, penelitian ini bertujuan untuk menguji pengaruh gaya hidup (Priceoriented, Net-oriented, Time-oriented, Innovative lifestyle) terhadap keputusan pembelian tiket elektronik di situs Tiket.com. Sampel sebanyak 102 responden ditetapkan mengacu pada kriteria teknik purposive sampling. Untuk mengukur signifikansi variabel prediktor, analisis SEM (Structural Equation Model) - PLS (Partial Least Square) diterapkan. Hasilnya menunjukkan bahwa variabel gaya hidup yaitu price-oriented dan time-oriented tidak memiliki dampak signifikan terhadap keputusan pembelian online di Tiket.com dan bertentangan dengan temuan dari penelitian sebelumnya. Implikasi penelitian diharapkan dapat memerkaya studi selanjutnya dan dapat mengembangkan strategi e-commerce di Indonesia.
\end{abstract}

Kata Kunci: Gaya Hidup, Keputusan Pembelian Online, Perilaku Konsumen Online, Ecommerce

How Lifestyle affects Online Ticket Purchasing Decisions?

\section{ABSTRACT}

Reflecting on netizen lifestyle and shifting behavior phenomena in e-commerce platform, this study appoints to examine the influence of lifestyle (Price-oriented, Net-Oriented, Time-Oriented, Innovative) toward e-ticket purchasing decisions in Tiket.com. A total sample of 102 respondent was stipulated refer to purposive sampling technique criterion. To measure the significance of the predictors variable, SEM (Structural Equation Model) - PLS (Partial Least Square) analysis was applied. The outcome show that Price-oriented and Time-oriented Lifestyle has no significant impact on online purchasing decision in Tiket.com and is contradict with the findings from prior research. The implications of the results are expected to enrich future studies and develop e-commerce strategies in Indonesia.

Keywords: Lifestyle, Online Purchasing Decision, Online Consumer Behaviour, E-commerce

Cara Sitasi:

Ashoer, M., Syahnur, H., Murdifin, I. (2019). Bagaimana Gaya Hidup mempengaruhi Keputusan Pembelian Tiket Online?. Jurnal Ilmiah Manajemen dan Bisnis, 20(1), 39-51. https://doi.org/10.30596/jimb.v20i1.2493 


\section{JURNAL ILMIAH MANAJEMEN DAN BISNIS}

\section{PENDAHULUAN}

Gaya hidup (lifestyle) merupakan salah satu ceruk pasar potensial yang menyasar segmen psikografis konsumen. Lifestyle mengacu pada bagaimana seseorang hidup, atau cara khas seseorang hidup (Horley, Carroll, \& Little, 1988). Kotler dan Amstrong (2012) menambahkan gaya hidup mencakup pola dimana orang hidup dan menggunakan uang dan waktunya serta memengaruhi seluruh aspek dari perilaku konsumsi seseorang. Pendekatan terhadap lifestyle memuat 3 dimensi penting, yaitu: activities, interest dan opinions (Al-Dmour et al., 2017; Plummer, 1974). Lifestyle menyediakan pandangan yang lebih luas mengenai konsumen sehingga pemasar dapat menyasar konsumen dengan lebih efektif. Alasan utama dari penelitian mengenai lifestyle adalah semakin pemasar mengerti dan memahami konsumen, maka pemasar akan dapat berkomunikasi dan melayani konsumen dengan lebih baik. Asumsi yang mendasari ini adalah bahwa konsumen mengekspresikan kepribadian mereka melalui perilaku. Jadi pendekatan lifestyle mampu mewujudkan tindakan yang efektif bagi pemasar kepada konsumennya, termasuk konsumen potensial.

Beberapa penelitian terdahulu telah menelaah bagaimana variabel lifestyle memengaruhi keputusan pembelian $e$ commerce. Kim, Rao, \& Cho (2000) membentuk suatu model konseptual baru mengenai pengaruh consumer lifestyle terhadap perilaku pembelian di internet. Model ini dikembangkan karena kurangnya penelitian mengenai mengapa konsumen memilih untuk berbelanja secara online. Penelitian ini menemukan bahwa pembelian online dipengaruhi oleh net-oriented style lamanya konsumen terbiasa menggunakan internet dan kinerjanya terbantu karena adanya internet, dan time-oriented style waktu konsumen yang semakin sedikit karena kesibukan dunia kerjanya sehingga membutuhkan fleksibilitas waktu dalam berbelanja.

Studi Atchariyachanvanich \& Okada (2007) di Jepang memerbaharui konsep awal yang dibentuk oleh Kim et al. (2000) dengan menambahkan variabel innovative lifestyle. Hasil penelitian menemukan bahwa ternyata kebiasaan orang untuk menggunakan internet dalam aktivitasnya (net-oriented lifestyle) dan kemampuan seseorang untuk menerima dan mengadopsi perubahan teknologi (innovative lifestyle) tidak berpengaruh signifikan terhadap perilaku pembelian secara online. Hasil ini memiliki perbedaan (inkonsistensi) dengan beberapa penelitian terdahulu dimana gaya hidup berbasis inovasi memengaruhi perilaku pembelian secara online.

Temuan lainnya dimuat dalam studi Brashear dkk,. (2009) tentang profil konsumen yang melakukan online shopping di 6 (enam) negara yang berbeda, yaitu Amerika Serikat, Inggris, China, Brazil, New Zealand dan Bulgaria. Kondisi demografis dari tiap-tiap negara memiliki perbedaan, namun tetap ditemukan banyak kesamaan karasteristik. Hasil serupa ditemukan dalam penelitian di Taiwan, dimana konsumen akan melakukan online shopping karena mencari harga yang lebih murah (Lien et al., 2015). Penelitian Bagdoniene \& Zemblyte (2015) juga menemukan hasil yang relevan tentang motivasi konsumen di Lithuania dalam melakukan online shopping yaitu kemampuan untuk dapat berbelanja kapanpun, dan dimanapun karena kesibukan sehari-hari. Ditemukan juga, apabila harga di internet lebih tinggi maka akan menurunkan motivasi untuk berbelanja online.

Studi spesifik mengenai lifestyle dan online shopping telah banyak dilakukan, hasil yang ditemukan pun cukup beragam. Misalnya, penelitian Al-Dmour et al. (2017) tentang keputusan penumpang pesawat di Jordania membeli tiket pesawat (e-tickets) secara online. Kemudian studi Maharani \& 
Sevriana (2017) terhadap konsumen milenial (rentang usia 15-25 tahun) di Indonesia (Bandung) yang melakukan transaksi online melalui media sosial Instagram. Dan temuan Mohiuddin (2018) tentang mayoritas konsumen wanita di Pakistan yang cenderung lebih memilih barang-barang impor branded (bermerek) dibandingkan dengan barangbarang lokal dalam ruang lingkup $e$ commerce. Umumnya, pemaparan ketiga penelitian di atas menyimpulkan bahwa keinginan konsumen untuk berbelanja online dipengaruhi oleh penerimaan dan adopsi konsumen dalam menerima inovasi baru. Sehingga konsumen yang demikian tergolong sebagai konsumen yang inovatif. Perbedaan temuan pada penelitian yang satu dengan yang lainnya memperkaya wawasan dalam mengembangkan teori-teori yang terkait. Beberapa penelitian tidak membatasi produk yang diteliti terkait dalam pembelian secara online. Selain itu, tidak banyak penelitian yang khusus membahas mengenai gaya hidup, atau yang terkait dengan ilmu pemasaran. Sedangkan pada kenyataannya, gaya hidup sangat erat kaitannya dengan sikap, tindakan, dan perilaku konsumen.

Penelitian ini dilakukan untuk menganalisis dampak gaya hidup dalam kajian ilmu pemasaran, yaitu mengenai pengaruhnya terhadap perilaku pembelian online. Obyek kajian yang secara spesifik dipilih untuk memperoleh pemahaman mendalam mengenai sebuah fenomena ialah situs Tiket.com. PT Global Tiket Network merupakan perusahaan e-commerce yang memiliki fokus pada fitur booking dan transaksi online yang memberikan layanan reservasi e-ticket. Situs Tiket.com tercatat telah melayani jasa pemesanan tiket pesawat, kereta api, hotel, entertainment (tiket konser musik, festival, pertandingan olahraga, seminar, dan lain-lain), nonton bioskop, dan bahkan sewa mobil. Untuk menunjang kebutuhan dan keinginan pelanggan, tampilan situs portal telah di-upgrade dengan desain yang lebih modern namun tetap sederhana. Keunikan dari reservasi tiket pesawat lewat Tiket.com adalah konsumen dapat memesan tiket penerbangan pulang pergi dari dua maskapai berbeda, namun sistem pembayarannya cukup melalui situs Tiket.com. Hal ini tentu semakin memberikan kemudahan/ kepraktisan dalam penggunaanya (ease of use), atau salah satu faktor penentu perilaku pembelian online.

Penelitian ini dilatarbelakangi oleh semakin pesatnya pertumbuhan pengguna internet sehingga menggeser pola/ perilaku pembelian konsumen yang tradisional faceto-face ke pembelian secara online atau melakukan pembelian pada situs online, khususnya $e$-tickets. Memaksimalkan faktorfaktor determinan perilaku pembelian online warganet menjadi sebuah kebutuhan yang tidak dapat dielakkan, pemahaman terhadap berbagai macam perubahan-perubahan internal maupun eksternal yang terjadi dalam diri konsumen menjadi isu penting bagi pelaku e-commerce.

E-commerce merupakan aktifitas pertukaran antara 2 (dua) pihak atau lebih dengan menggunakan media internet (Laudon \& Traver, 2014). Mode perdagangan ini menggeser perilaku pembelian konsumen dari pasar konvensional menjadi serba praktis (Ashur, 2016). Lebih spesifik lagi, usaha retail yang dilakukan dengan menggunakan media internet, disebut electronic retailing atau e-tailing, dan siapapun yang melangsungkan bisnis secara online disebut $e$ tailers. E-tailing memudahkan bagi produsen untuk secara langsung menjual kepada konsumen, dengan memotong perantara (Turban et al., 2015).

Teori perilaku konsumen sebelumnya menjelaskan bahwa keputusan pembelian dipengaruhi oleh berbagai faktor, salah satunya ialah lifestyle. Kim, Rao, \& Cho (2000) mengemukakan sebuah konsep baru mengenai gaya hidup konsumen yang berkaitan dengan penggunaan internet sebagai 


\section{JURNAL ILMIAH MANAJEMEN DAN BISNIS \\ ISSN 1693-7619 (print) | ISSN 2580-4170 (online), http://jurnal.umsu.ac.id/index.php/mbisnis}

salah satu media belanja. Penelitian tersebut mengategorikan lifestyle ke dalam 3 (tiga) kategori yang berbeda, yaitu: price-oriented, net-oriented, dan time-oriented lifestyle. Kemudian, merujuk pada teori Difusi Inovasi, Atchariyachanvanich \& Okada (2007) menambahkan variabel baru, yaitu innovative lifestyle. Beberapa penelitian menunjukkan bahwa konsumen melakukan pembelian menggunakan media internet karena berusaha mencari harga yang lebih murah daripada toko fisik (Lien et al., 2015). Kesibukan sehari-hari membuat orang semakin sulit untuk menyesuaikan waktu berbelanja sehingga konsumen cenderung melakukan pembelian pada toko ritel online (Atchariyachanvanich \& Okada, 2007; Bagdoniene \& Zemblyte, 2015). Studi selanjutnya menemukan bahwa frekuensi penggunaan internet turut berkontribusi dalam keputusan pembelian online (Mohamed et al., 2014) dan mereka tergolong dalam konsumen yang inovatif (Brashear et al., 2009). Mengacu pada alur pemaparan di atas, maka kerangka konseptual yang diajukan dalam penelitian ini dapat dilihat pada Gambar 1.

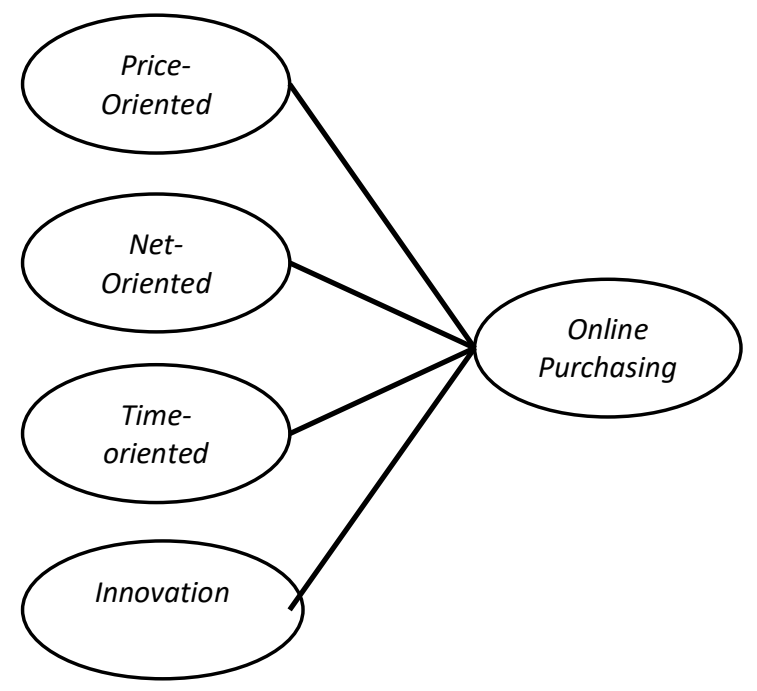

Gambar 1. Kerangka Konseptual Penelitian
Price-oriented lifestyle dalam perspektif pemasaran menunjukkan perilaku konsumen yang cenderung berorientasi terhadap harga jual produk (Atchariyachanvanich \& Okada, 2007). Banyak konsumen yang sensitif terhadap harga, secara aktif mencari dan membeli produk di internet karena harga yang lebih murah, termotivasi untuk membandingkan harga dari berbagai alternatif, selain dengan membandingkan sesama toko di internet, juga untuk membandingkan dengan toko tradisional (Kim, Rao, \& Cho, 2000). Perilaku membandingkan untuk mendapat harga lebih murah merupakan motivasi yang mendorong individu untuk melakukan online shopping (Lien et al., 2015). Penawaran harga di internet dapat lebih murah dari toko tradisional karena beberapa alasan, salah satunya toko online menghemat biaya pengadaan toko (To, Liao, \& Lin, 2007). Selain itu, konsumen tertarik untuk membeli secara online karena ada penawaran promosi yang berdampak impulsive pada niat belanjaonline. Bahkan, penawaran ini dapat berupa sampel gratis, bonus atas suatu pembelian tertentu, pemberian kupon $(\mathrm{Xu} \&$ Huang, 2014).

Berdasarkan uraian di atas, maka dikemukakan hipotesis sebagai berikut:

$H 1$ - Price-oriented lifestyle memiliki pengaruh terhadap perilaku pembelian online

Net-oriented lifestyle ditunjukkan dengan lamanya penggunaan internet, penggunaan email baik mengirim maupun menerima email, dan penggunaan teknologi komunikasi yang dapat menunjang produktivitas kerja manusia (Kim, Rao, \& Cho, 2000). Konsep ini dapat juga dinyatakan sebagai keyakinan seseorang akan kemampuannya untuk mengatur dan dapat menggunakan internet. Pengetahuan konsumen terhadap komputer dan internet serta frekuensi dan lama penggunaan internet secara positif memengaruhi perilaku 
konsumen terhadap belanja online (Mohamed et al., 2014). Individu yang terbiasa dengan penggunaan internet memungkinkan baginya untuk mampu melakukan pembelian melalui internet. Pengguna internet yang menghabiskan banyak waktunya untuk menjelajahi internet, dan memiliki waktu yang lebih lama dalam menggunakan internet akan lebih terbiasa dengan tawaran-tawaran yang ada pada internet dan memiliki pengetahuan yang lebih untuk menggunakannya sebagai salah satu shopping channel yang baru.

Mengacu pada pemaparan di atas, maka dirumuskan hipotesis sebagai berikut: H2 - Net-oriented lifestyle memiliki pengaruh terhadap perilaku pembelian online.

Berbagai macam motivasi dapat mendasari mengapa konsumen melakukan pembelian melalui internet. Salah satu motivasi yang telah terbukti konsumen memilih untuk membeli melalui internet adalah karena kesibukan sehari-harinya. Jumlah jam kerja atau kesibukan individu sehari-hari memungkinkan individu untuk merasa kelelahan dan memiliki sedikit waktu untuk berbelanja, dan kebanyakan orang menjadi susah untuk keluar dari rumah mereka untuk berbelanja (Mohamed et al., 2014). Menghabiskan waktu di toko fisik, atau berbelanja secara tradisional akan cukup menyita tenaga dan waktu (Kim, Rao, \& Cho, 2000), antara lain seperti harus menghadapi keramaian, antrian di kasir, dan berebut tempat parkir di mall yang ramai (Ahmad, Omar, \& Ramayah, 2010).

Konsumen dapat melakukan pembelian secara online karena kenyamanan yang dicari, yaitu memungkinkan mereka melakukan transaksi kapanpun dan dimanapun mereka berada. Kebanyakan pembeli online berusaha untuk menghemat waktunya dengan tujuan untuk meningkatkan kualitas hidupnya dan mengurangi waktu yang dihabiskan untuk berbelanja menjadi salah satu pilihan utama konsumen (Bagdoniene \& Zemblyte, 2015), atau dengan kata lain individu akan melakukan pembelian di internet karena menghemat waktunya (Al-Dmour et al., 2017).

Berdasarkan pernyataan di atas, maka penelitian ini mengajukan hipotesis sebagai berikut:

H3 - Time-oriented lifestyle memiliki pengaruh terhadap perilaku pembelian online.

Pendekatan pemasaran yang berorientasi pasar menilai inovasi sebagai sejauh mana para konsumen terbuka terhadap produk baru. Midgley dan Dowling dalam Bigné-Alcañiz et al. (2008) mendefinisikan inovasi sebagai suatu tingkatan dimana individu menerima ide-ide baru dan membuat keputusan inovatif yang mandiri tanpa terkait dari pengalaman individu lain. Pernyataan ini termasuk juga mengenai bagaimana individu menerima online shopping sebagai salah satu shopping channel baru. Beberapa penelitian menunjukkan bahwa konsumen yang melakukan belanja melalui e-commerce adalah konsumen inovatif yang memiliki gaya hidup terhadap perubahan termasuk dengan penerimaan terhadap penggunaan internet sebagai media belanja yang baru (Brashear et al., 2009; Hur, Kyung Kim, \& Park, 2010; Warayuanti \& Suyanto, 2015).

Berdasarkan uraian di atas, maka hipotesis yang dikemukakan adalah sebagai berikut:

H4 - Innovative lifestyle memiliki pengaruh terhadap perilaku pembelian online.

\section{METODE}

Penelitian ini dikategorikan dalam desain penelitian penjelasan (explanatory research) (Sekaran \& Bougie, 2017). Populasi dalam penelitian ini adalah konsumen yang pernah melakukan pembelian pada situs Tiket.com, baik itu secara langsung melalui website maupun mobile app (aplikasi). Situs ini dipilih karena mampu mencatatkan puluhan ribu transaksi setiap 
hari, ditambah dengan angka traffic pencarian yang tinggi dalam mesin pencarian (seperti yahoo dan google) dengan kisaran 9.000 10.000 unique new visitors. Mengingat populasi tidak dapat dihitung (uncountable), maka teknik penentuan sampel menggunakan purposive sampling (Zikmund, 2013).

Kriteria responden yang ditetapkan dalam menentukan sampel ialah konsumen yang melakukan transaksi minimal dua kali pada periode Desember 2017 hingga Mei 2018, ini merupakan data termutakhir yang diharapkan dapat menunjukkan bentuk perilaku pembelian online yang baru. Penentuan sampel selaras dengan model analisis yang digunakan yaitu Structural Equation Model (SEM) berbasis varian PLS. Ukuran sampel untuk SEM yang menggunakan model estimasi maximum likelihood estimation (MLE) adalah 100-200 sampel (Hair et al., 2017) atau sebanyak 5 10 kali jumlah indikator yang diuji (Becker \& Ismail, 2016). Mengacu pada penjelasan di atas, maka jumlah sampel minimum adalah sebesar 20 (item) x 5 (konstruk) $=100$ responden. Total responden yang berpartisipasi dalam survei online tercatat sebanyak 144 orang, namun setelah melalui proses penyaringan hanya 102 pelanggan Tiket.com yang memenuhi kriteria teknik purposive sampling yang telah ditetapkan sebelumnya.

Data primer yang valid dan reliable diperoleh dengan menggunakan teknik pengumpulan data sebagai berikut: (1) Survei online; Evans \& Mathur (2005) merekomendasikan metode ini karena dianggap memiliki beberapa kelebeihan misalnya biaya rendah, jangkauan responden lebih besar, dan mudah diaplikasikan, (2) Proses diseminasi kuisioner dilakukan dengan membagikan link ke media social seperti facebook, whatsapp, email, dan media internet lainnya, (3) Rancangan kuesioner terdiri dari dua bagian yaitu karasterisktik responden dan data pengukuran variabel. Data responden terdiri dari nama, jenis kelamin, usia, wilayah tempat tinggal, pekerjaan, intensitas dalam mengakses Tiket.com, dan jenis tiket yang sering dibeli, sedangkan data pengukuran variabel memuat deskripsi jawaban kuisioner responden.

Penggunaan SEM-PLS dalam penelitian ini didasarkan pada beberapa pertimbangan yaitu (1) PLS dapat digunakan untuk menguji efek prediksi hubungan antar variabel laten, (2) PLS tidak mensyaratkan data terdistribusi normal (indikator dengan skala kategori, ordinal, interval sampai ratio dapat digunakan pada model yang sama), sampel tidak harus besar, dan pendekatan regresi (analisis path) berbasis varian lebih cocok digunakan dibandingkan dalam SEM yang berbasis kovarian seperti AMOS dan LISREL. (Rigdon, Sarstedt, \& Ringle, 2017). Model evaluasi SEM berbasis PLS terbagi ke dalam 2 (dua) bagian yaitu outer model dan inner model.

\section{HASIL DAN PEMBAHASAN}

Deskripsi responden yang telah melakukan pembelian e-tickets pada Tiket.com dimuat dalam Tabel 1. Mayoritas responden merupakan laki-laki kisaran umur $31-40$ tahun, dengan status pekerjaan sebagai pegawai swasta, dan memiliki pendapatan antara $3-5$ juta perbulannya. Dominan responden telah telah menggunakan internet selama lebih dari 3 tahun. Secara singkat, responden digolongkan dalam segmen berpendapatan menengah keatas (mapan), dan memiliki pengetahuan dan pengalaman yang matang terhadap pemanfaatan internet. Segmentasi memainkan peran vital bagi pemasar $e$ commerce dalam menentukan strategi target dan positioning merek ke dalam benak konsumen. 
Tabel 1. Demografi Resposden $(\mathrm{N}=102)$

\begin{tabular}{llcc}
\hline \multicolumn{1}{c}{ Atribut } & \multicolumn{1}{c}{ Item } & F & $\%$ \\
\hline Jenis & Laki-laki & 65 & $63.7 \%$ \\
Kelamin & Perempuan & 37 & $37.3 \%$ \\
Umur & $21-30$ & 37 & $36.2 \%$ \\
& $31-40$ & 49 & $48 \%$ \\
Pekerjaan & $41-50$ & 16 & $15.8 \%$ \\
& PNS & 22 & $21.6 \%$ \\
& Pegawai & 38 & $37.2 \%$ \\
& Swasta & & \\
& Wiraswasta & 32 & $32.3 \%$ \\
Pendapatan & Lainnya & 10 & $9.8 \%$ \\
& 1-3 Juta & 13 & $12.7 \%$ \\
& 3 - 5 Juta & 60 & $58.9 \%$ \\
Penggunaan & $>5$ Juta & 29 & $28.4 \%$ \\
Internet & 1 1 tahun & 7 & $6.8 \%$ \\
& 1-5 tahun & 21 & $20.5 \%$ \\
& $>5$ tahun & 72 & $70.6 \%$
\end{tabular}

Evaluasi model SEM-PLS pertama dalam outer model (pengukuran bagian luar) adalah pengukuran reflektif yang dinilai dengan menggunakan validitas dan realibilitas. Penggolongan evaluasi validitas terbagi ke dalam 2 (dua) kriteria, yaitu validitas konstruk dilakukan dengan menghitung validitas konvergen dan validitas diskriminan.

Validitas konvergen merupakan seperangkat indikator/ item yang mewakili satu variabel laten (unobserved) dan yang mendasari variabel tersebut. Validitas konvergen diketahui melalui loading factor. Suatu instrument dikatakan memenuhi kriteria pengujian validitas konvergen apabila memiliki faktor loading di atas 0.7 (Garson, 2016). Berdasarkan hasil pengujian dapat diketahui bahwa semua item yang mengukur variabel memiliki nilai lebih besar dari 0.7. Dengan demikian item tersebut dinyatakan valid untuk mengukur konstruknya.

Validitas diskriminan dihitung menggunakan cross loading, dengan kriteria bahwa apabila korelasi antara variabel laten dengan setiap indikatornya (variabel manifest) lebih besar daripada korelasi dengan variabel laten lainnya, maka variabel laten tersebut dapat disimpulkan memprediksi indikatornya lebih baik daripada variabel laten lainnya (Garson, 2016). Berdasarkan pengukuran cross loading pada tabel 3 di atas, dapat dijelaskan bahwa keseluruhan item yang mengukur variabel menghasilkan nilai loading yang lebih besar dibandingkan dengan nilai loading pada variabel lainnya. Dengan demikian dapat dinyatakan bahwa masing-masing item mampu mengukur variabel laten yang bersesuaian dengan item tersebut.

Pengujian realibilitas konstruk dalam outer model diukur mengacu pada nilai diskriminan reliability (AVE), cronbach alpha dan composite reliability. Kriteria pengujian menyatakan bahwa apabila diskriminan reliability ( $A V E$ ) bernilai lebih besar dari 0.5, composite reliability (C.R.) bernilai lebih besar dari 0.7, dan cronbach alpha $(\alpha)$ bernilai lebih besar dari 0.6, maka konstruk tersebut dinyatakan reliabel (Hair et al., 2017). Hasil perhitungan diskriminan reliability, cronbach alpha dan composite reliability dapat dilihat melalui ringkasan (overview) yang disajikan dalam tabel 2 berikut ini:

Tabel 2. Ringkasan Hasil Uji

\begin{tabular}{ccccc}
\hline & Items & $\boldsymbol{A V E}$ & $\boldsymbol{C .} \boldsymbol{R}$. & $\boldsymbol{\alpha}$ \\
\hline PoL & 5 & 0,627 & 0,894 & 0,851 \\
NoL & 3 & 0,670 & 0,858 & 0,752 \\
ToL & 5 & 0,580 & 0,873 & 0,818 \\
IL & 5 & 0,636 & 0,897 & 0,857 \\
OP & 2 & 0,674 & 0,804 & 0,521 \\
\hline
\end{tabular}

Hasil pengujian, dapat diketahui bahwa masing-masing nilai dari variabel konstruk telah memenuhi kriteria ambang batas yang ditetapkan yaitu AVE > 0,5, C.R.> 0.7, dan $\alpha$ $>0,6$, maka dapat disimpulkan semua item dinyatakan reliabel dalam mengukur variabel latennya.

Uji model Goodness of fit (GFI) merupakan kriteria evaluasi model 


\section{JURNAL ILMIAH MANAJEMEN DAN BISNIS \\ ISSN 1693-7619 (print) | ISSN 2580-4170 (online), http://jurnal.umsu.ac.id/index.php/mbisnis}

pengukuran struktural. GFI menggambarkan besarnya kontribusi variabel eksogen terhadap variabel endogen. Hasil uji menunjukkan bahwa nilai $R$-squared $\left(\mathrm{R}^{2}\right)$ sebesar 0,532 atau $53.2 \%$. Hal ini dapat menunjukkan bahwa keragaman variabel online purchasing mampu dijelaskan oleh variabel price-oriented, net-oriented, timeoriented, dan innovative lifestyle sedangkan sisanya sebesar $46.8 \%$ merupakan kontribusi variabel lain yang tidak dibahas dalam penelitian ini.

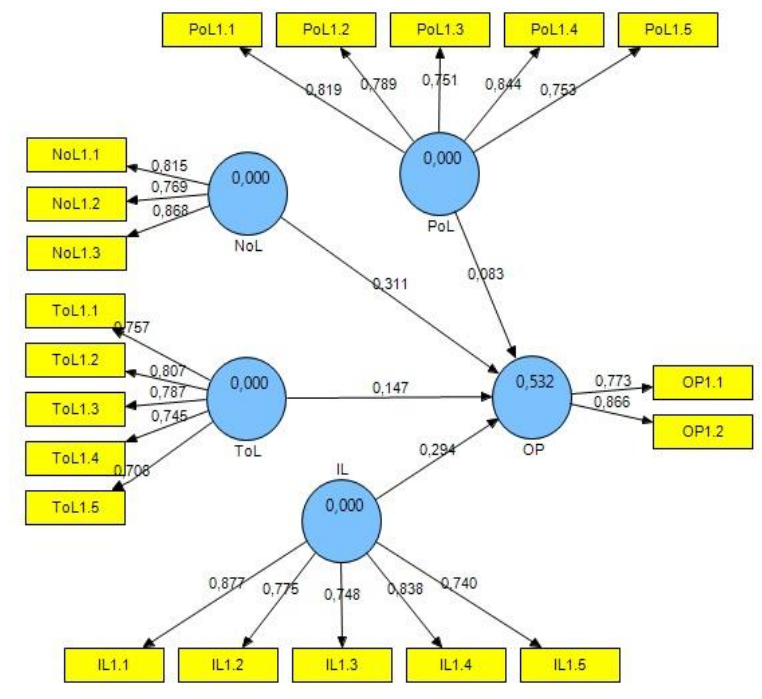

Gambar 2. Hasil Konstruksi Model

Pengujian hipotesis (signifikansi) pada metode analisis SEM-PLS menyebutkan bahwa nilai estimasi untuk hubungan jalur (koefisien) dalam pengukuran struktural model digunakan untuk mengetahui signifikansi dari hubungan-hubungan antar variabel laten.

Uji hipotesis dilakukan dengan cara melakukan proses bootstrapping dengan bantuan program software komputer smartPLS 3.0 sehingga diperoleh hubungan pengaruh variabel eksogen terhadap variabel endogen. Nilai T-tabel untuk tingkat kepercayaan sebesar 95\% ( $\alpha$ sebesar 5\%) dan derajat kebebasan $(\mathrm{df})=\mathrm{n}-2=102-2=100$ adalah sebesar 1,98. Pengujian hipotesis untuk masing-masing hubungan variabel laten disajikan sebagai berikut:

Tabel 3. Ringkasan Hasil Uji Hipotesis

\begin{tabular}{lcccc}
\hline & $\boldsymbol{O}$ & $\begin{array}{c}\text { Nilai T- } \\
\text { Statistik }\end{array}$ & $\begin{array}{c}\text { Cut- } \\
\text { off }\end{array}$ & Ket. \\
\hline PoL $\rightarrow$ OP & 0,083 & 0,730 & 1,98 & TS \\
NoL $\rightarrow$ OP & 0,311 & 2,821 & 1,98 & $* *$ \\
ToL $\rightarrow$ OP & 0,147 & 1,302 & 1,98 & TS \\
IL $\rightarrow$ OP & 0,294 & 2,218 & 1,98 & $*$ \\
\hline
\end{tabular}

Ket:TS: Tidak Signifikan, Sig: $* \alpha<0,05,{ }^{* *} \alpha<$ 0,01

H1 - Price-oriented lifestyle memiliki pengaruh terhadap perilaku pembelian online Berdasarkan hasil output pada Tabel 3, nilai original sample estimate $(\mathrm{O})$ variabel price-oriented lifestyle (PoL) menunjukan nilai sebesar 0,083 yang berarti bahwa arah hubungan variabel adalah positif. Sedangkan nilai T-statistik variabel PoL terhadap variabel pembelian online $(\mathrm{OP})$ sebesar 0,730 atau lebih kecil dari T-tabel $(1,98)$. Artinya, variabel laten PoL tidak memiliki pengaruh signifikan terhadap variabel laten OP. Dengan demikian $\mathrm{H} 1$ ditolak.

H2 - Net-oriented lifestyle memiliki pengaruh terhadap perilaku pembelian online.

Berdasarkan hasil output pada Tabel 3, nilai original sample estimate $(\mathrm{O})$ variabel net-oriented lifestyle (NoL) menunjukan nilai sebesar 0,311 yang berarti bahwa arah hubungan variabel adalah positif, dan nilai Tstatistik variabel NoL terhadap variabel pembelian online (OP) sebesar 2,821 atau lebih besar dari T-tabel (1,98). Artinya, variabel laten NoL berpengaruh signifikan terhadap variabel laten OP. Dengan demikian $\mathrm{H} 2$ diterima. 
H3 - Time-oriented lifestyle memiliki pengaruh terhadap perilaku pembelian online

Berdasarkan hasil output pada Tabel 3, nilai original sample estimate $(\mathrm{O})$ variabel time-oriented lifestyle (ToL) menunjukan nilai sebesar 0,147 yang berarti bahwa arah hubungan positif. Nilai T-statistik variabel ToL terhadap variabel pembelian online (OP) yaitu sebesar 1,302 atau lebih kecil dari Ttabel (1,98). Artinya, variabel ToL tidak berpengaruh signifikan terhadap variabel OP. Dengan demikian H3 ditolak.

H4 - Innovative lifestyle memiliki pengaruh terhadap perilaku pembelian online

Berdasarkan hasil output pada Tabel 3, nilai original sample estimate $(\mathrm{O})$ variabel innovative lifestyle (IL) menunjukan nilai sebesar 0,294 yang berarti bahwa arah hubungan positif, dan nilai $\mathrm{T}$ statistik variabel IL sebesar 2,218 atau lebih besar dari nilai Ttabel $(1,98)$. Artinya, variabel IL berpengaruh signifikan terhadap online purchasing (OP). Dengan demikian H4 diterima.

\section{Pembahasan}

Temuan penelitian menunjukkan bahwa variabel prediktor yang diteliti tidak semuanya memengaruhi perilaku pembelian online. Terdapat masing-masing 2 (dua) variabel yang menunjukkan pengaruh signifikan dan tidak signifkan terhadap perilaku pembelian online konsumen. Pengaruh signifikan ditemukan pada variabel net-oriented lifestyle (NoL) dan innovative lifestyle (IL) sedangkan variabel price-oriented ( $\mathrm{PoL})$ dan timeoriented lifestyle (ToL) tidak memiliki pengaruh signifikan terhadap perilaku pembelian online. Ditinjau dari nilai koefisien masing-masing prediktor, variable NoL memiliki estimasi tertinggi atau pengaruh dominan, hal ini mengindikasikan bahwa pengalaman dan pengetahuan responden dalam transaksi e-commerce Tiket.com merupakan faktor penentu utama dalam membentuk perilaku pembelian $e$ tickets.

\section{Price-oriented lifestyle tidak berpengaruh signifikan terhadap perilaku pembelian online.}

Price-oriented lifestyle (PoL) menggambarkan perilaku pelanggan yang memiliki kecenderungan lebih terhadap harga dan kebijakan yang berkaitan dengan penawaran harga produk. Koefisien jalur dan Nilai $\mathrm{T}$ statistik variabel PoL menunjukkan arah positif namun tidak berpengaruh signifikan terhadap keputusan pembelian online, artinya intensitas penawaran harga berbanding lurus namun tidak berdampak signifikan terhadap keputusan pembelian online konsumen terhadap e-tickets yang ditawarkan $e$ commerce Tiket.com. Temuan ini bertentangan dengan penelitian terdahulu yaitu Kim et al. (2000), To et al. (2007), Atchariyachanvanic \& Okada (2007), Xu \& Huang (2014), dan Lien et al. (2015). Strategi harga khususnya dari segi penetapan harga yang ditawarkan oleh Tiket.com dinilai belum memenuhi ekspetasi pelanggan. Factor loading item penawaran harga $\left(\mathrm{PoL}_{1.3}\right)$ memiliki nilai paling rendah dibandingkan dengan item lainnya. Mereka menilai bahwa harga $e$-tickets di Tiket.com belum tentu lebih terjangkau jika dibandingkan dengan situs lain, sehingga memunculkan keraguan dari dalam diri konsumen untuk melakukan transaksi. Sikap ini juga membuat konsumen melakukan perbandingan harga baik itu antara sesama situs e-tickets maupun antara offline (konvensional) dan online. Kekhawatiran pelanggan Tiket.com juga bertumpu pada disparitas harga sesama perusahaan pesaing $e$ commerce berbasis e-tickets misalnya Traveloka.com, PegiPegi.com, dan sejenisnya. Ketika konsumen melakukan seleksi pada berbagai tingkatan harga atas produk yang sama, mereka akan mengevaluasi dan membandingkan harga 
sebagai referensi untuk melakukan transaksi pembelian. Karasteristik responden dalam penelitian ini juga mendukung kemampuan konsumen dalam mencari informasi mengenai harga yang sesuai dimana mayoritas pelanggan telah melakukan transaksi online minimal 2 (dua) kali. Faktor lainnya berupa program pemberian potongan harga (diskon dan bonus) juga dianggap belum maksimal memengaruhi keputusan pembelian. Tingkat pengalaman dan pengetahuan pelanggan dalam membandingkan promo-promo $e$ tickets terbaik turut menentukan apakah pilihan pelanggan jatuh kepada layanan Tiket.com atau sebaliknya. Manajemen Tiket.com dapat memberikan programprogam penawaran harga yang terjangkau kepada pelanggan agar dapat bersaing dengan situs e-tickets lainnya.

\section{Net-oriented lifestyle berpengaruh signifikan terhadap perilaku pembelian online.}

Net-oriented lifestyle (NoL) merujuk pada konsumen yang telah terbiasa menggunakan internet dalam kesehariannya. Koefisien jalur dan Nilai T statistik variabel NoL diketahui memiliki arah positif dan pengaruh signifikan terhadap keputusan pembelian pelanggan Tiket.com, artinya pengetahuan dan pengalaman $e$ commerce memberikan pengaruh terhadap keputusan pembelian online. Temuan ini terbukti konsisten dengan beberapa penelitian yang sebelumnya diungkap oleh Kim et al. (2000), Atchariyachanvanic \& Okada (2007) dan Mohamed et al. (2014), menyatakan bahwa individu dengan rutinitas pemanfaatan internet yang tinggi akan meningkatkan probabilitas pembelian melalui internet, atau online purchasing. Deskripsi jawaban pelanggan Tiket.com yang diteliti menunjukkan bahwa rata-rata mereka telah menggunakan internet selama lebih dari 3 tahun. Konsekuensinya, pengguna internet yang menghabiskan waktu lebih lama di dunia maya akan lebih banyak terpapar oleh berbagai macam tawaran-tawaran situs e-commerce berbasis $e$-tickets dan informasi - informasi penting berkaitan dengan format belanja online. Variabel NoL merupakan variabel yang dominan dalam memengaruhi pembelian online dibandingkan dengan variabel laten lainnya. Persepsi ini muncul mengingat pengalaman positif yaitu kenyamanan pelanggan $\left(\mathrm{NoL}_{3.3}\right)$ dalam melakukan pencarian informasi penawaran e-tickets di situs Tiket.com. Jawaban responden pada item tersebut memilki factor loading tertinggi dibandingkan dengan item lainnya. Mengingat mayoritas pelanggan Tiket.com merupakan pegawai dan wiraswasta dengan segudang kesibukan dan aktivitas, maka untuk memertahankan tren positif ini, manajemen Tiket.com hendaknya menjaga kenyamanan pelanggan dalam mengakses situs melalui sistem pengendalian kualitas website secara berkala agar situs dapat terus diakses dengan mudah. Fitur-fitur yang terdapat pada situs Tiket.com diharapkan tidak menyulitkan proses pencarian informasi $e$ tickets.

\section{Time-oriented lifestyle tidak berpengaruh signifikan terhadap perilaku pembelian online.}

Konsumen yang memiliki kepedulian tinggi pada Time-oriented lifestyle (ToL) menyetujui bahwa mode belanja online menyediakan berbagai macam solusi dalam mengatur waktu belanja mereka. Koefisien jalur dan Nilai $T$ statistik variabel ToL menunjukkan arah positif namun tidak memiliki pengaruh signifikan terhadap keputusan pembelian online pelanggan Tiket.com. Hasil ini ditemukan tidak sejalan dengan studi Kim et al. (2000), Bagdoniene \& Zemblyte, (2009), Ahmad et al. (2010), 
Mohamed et al. (2014), dan Al-Dmoura et al. (2017) yang menyatakan bahwa waktu berpengaruh signifikan terhadap keputusan pembelian online.

Hal inkonsistensi tersebut dimungkinkan terjadi jika ditinjau kembali dari kondisi demografis dan psikografis pelanggan Tiket.com. Kapasitas (level) pengetahuan dan pengalaman mereka yang tergolong mumpuni justru membuat proses pencarian terkadang justru dilakukan secara utuh pelanggan terkadang melakukan perbandingan harga terlalu lama, sehingga mengakibatkan waktu yang dihabiskan untuk menyelesaikan 1 (satu) transaksi online akan memakan waktu lebih banyak. Selain itu, tingkat trust (kepercayaan) kepada situs e-commerce, atau tingkat kepuasan berbelanja secara nyata pada toko offline (konvensional) seperti kebutuhan melihat keberadaan fisik jasa yang diinginkan, bertanya langsung, dan kemungkinan kebutuhan quality time bersama keluarga atau teman saat melakukan pembelian secara offline. Untuk meminimalisir keadaan ini, manajemen Tiket.com dapat memaksimalkan kenyamanan konsumen dalam penggunaan aplikasi Tiket.com. Manajemen Tiket.com, misalnya menerapkan program promosi yang lebih intens jika konsumen melakukan transaksi melalui aplikasi mobile.

\section{Innovative lifestyle berpengaruh signifikan terhadap perilaku pembelian online.}

Innovative Lifestyle (IL)

mendeskripsikan perilaku yang menginginkan dan menerima sesuatu yang baru, dalam penelitian ini kaitannya adalah dengan perilaku menerima perkembangan teknologi dan internet sebagai media baru untuk berbelanja. Koefisien jalur dan Nilai $\mathrm{T}$ statistik variabel NoL diketahui memiliki arah positif dan pengaruh signifikan terhadap keputusan pembelian e-tickets pelanggan Tiket.com, artinya semakin inovatif sifat pelanggan, maka semakin besar pula kemungkinan untuk melakukan online purchashing. Hasil ini menguatkan studi Brashier et al. (2008), Hur et al. (2010), Warayuanti \& Suyanto (2015) dan AlDmoura et al. (2017), yang menunjukkan bahwa konsumen yang melakukan belanja online adalah konsumen yang inovatif, memiliki gaya hidup terbuka dengan berbagai kemungkinan sesuatu yang memiliki novelty (kebaruan), termasuk terhadap penggunaan internet sebagai media belanja yang baru. Mayoritas responden memiliki tingkat pendidikan dan pekerjaan yang cukup mapan untuk belajar sesuatu yang baru. Hasil kuisioner juga membuktikan bahwa mayoritas konsumen selalu berniat mencari sesuatu yang baru ( $\left.\mathrm{IL}_{4.1}\right)$, termasuk bertransaksi secara online di situs maupun aplikasi Tiket.com. Perusahaan diharapkan selalu mengakomodir keinginan pelanggan yang selalu menginginkan hal-hal baru dari setiap inovasi Tiket.com, misalnya tampilan website atau aplikasi mobile, serta program diskon, bonus, dan sejenisnya.

\section{SIMPULAN}

Berdasarkan hasil analisis dan alur pembahasan di atas, maka dapat disimpulkan bahwa penelitian ini berhasil membuktikan adanya pengaruh signifikan pada variabel laten net-oriented dan innovative-oriented lifestyle, dan hasil inkonsistensi pada pengaruh tidak signifikan variabel laten price-oriented dan time-oriented lifestyle, terhadap perilaku berbelanja online pelanggan Tiket.com. Perilaku orientasi lifestyle konsumen memainkan peran penting dalam menstimulasi keputusan pembelian online, sehingga penting bagi e-commerce untuk dapat memahami gaya hidup konsumen agar dapat mengambil langkah yang tepat sesuai dengan strategi pemasarannya.

Hasil dari penelitian ini memiliki 
implikasi manajerial bagi Tiket.com, khususnya bagi prediktor yang belum memberikan dampak signifikan terhadap pembelian online. Berkaitan dengan orientasi harga pelanggan, Tiket.com dapat memberikan program penawaran promo (bonus, diskon, dan sejenisnya) yang lebih intensif dan menarik atensi pelanggan. Perang harga antar sesama situs online yang menawarkan e-tickets menciptatkan persaingan yang kompetitif, sehingga untuk menggiring transaksi pelanggan jatuh kepada Tiket.com, maka strategi harga seharusnya memiliki kesesuaian dengan orientasi pelanggan. Selain itu, faktor orientasi waktu dalam melakukan pembelian online juga tidak berpengaruh signifikan. Tiket.com dapat mengoptimalkan proses transaksi dengan memangkas langkah-langkah dimana pelanggan tidak perlu meng-klik lebih banyak untuk melakukan pembelian online.

Temuan penelitian ini dapat memperkaya kajian teoritis mengenai lifestyle dengan memberikan sumbangsih pemikiran baru bagi dunia akademik. Namun, studi ini juga tidak lepas dari berbagai keterbatasan walaupun telah dilakukan menurut kaidah-kaidah metode penelitian. Keterbatasan pertama terletak pada cakupan objek penelitian yang hanya melibutkan satu toko online sehingga justifikasi terbatas pada situs online yang menawarkan jasa/ produk e-tickets. Penelitian mendatang dapat mencoba menambahkan atau mengolaborasikan objek-objek toko online untuk mendapatkan pemahaman yang lebih komperehensif. Keterbatasan terakhir ialah variabel prediktor, dimana studi selanjutnya dapat menambahkan variabel kepercayaan untuk memberikan pengaruh signifikan. Menambahkan item-item pernyataan yang berkaitan dengan trust untuk penelitian selanjutnya diharapkan dapat menyajikan ulasan yang lebih luas berkaitan dengan perilaku pembelian secara online.

\section{REFERENSI}

Ahmad, N., Omar, A., \& Ramayah, T. (2010). Consumer lifestyles and online shopping continuance intention. Business Strategy Series, 11(4), 227243.

https://doi.org/10.1108/1751563101106 3767

Al-Dmour, R., Hammdan, F., Al-Dmour, H., Alrowwad, A., \& Khwaldeh, S. M. (2017). The Effect of Lifestyle on Online Purchasing Decision for Electronic Services: The Jordanian Flying E-Tickets Case. Asian Social Science, $13(11), \quad 157$. https://doi.org/10.5539/ass.v13n11p157

Ashur, M. (2016). Pengaruh Dukungan Sosial, Persepsi Risiko Dan Interaksi Sosialterhadap Kepercayaan Dan Niat Pembelian Konsumen Pada Media SCommerce. Jurnal Bisnis Dan Manajemen, 3(1). https://doi.org/10.26905/JBM.V3I1.79

Atchariyachanvanich, K., \& Okada, H. (2007). How Consumer Lifestyles Affect Purchasing Behavior: Evidence from Internet Shopping in Japan. Journal of Entrepreneurship Research, 2(2), 63-78.

Bagdoniene, L., \& Zemblyte, J. (2015). Online Shopping Motivation Factors And Their Effect On Lithuanian Consumers. Economics And Management, O(14), 367-374. https://doi.org/10.5755/j01.em.0.14.939 2

Becker, J.-M., \& Ismail, I. R. (2016). Accounting for sampling weights in PLS path modeling: Simulations and empirical examples. European Management Journal, 34(6), 606-617. 


\section{JURNAL ILMIAH MANAJEMEN DAN BISNIS}

https://doi.org/10.1016/j.emj.2016.06.0

09

Bigné-Alcañiz, E., Ruiz-Mafé, C., AldásManzano, J., \& Sanz-Blas, S. (2008). Influence of online shopping information dependency and innovativeness on internet shopping adoption. Online Information Review, 32(5), $648-$ 667.https://doi.org/10.1108/146845208 10914025.

Brashear, T. G., Kashyap, V., Musante, M. D., \& Donthu, N. (2009). A Profile of the Internet Shopper: Evidence from Six Countries. Journal of Marketing Theory and Practice, 17(3), 267-282. https://doi.org/10.2753/MTP10696679170305.

Evans, J. R., \& Mathur, A. (2005). The value of online surveys. Internet Research, 15(2), 195-219. https://doi.org/10.1108/1066224051059 0360.

Garson, G. D. (2016). Partial Least Squares: Regression and Structural Equation Models. Asheboro, NC : Statistical Associates Publishers. https://doi.org/ISBN-13: 978-1-62638039-4.

Hair, J. F., Hult, G. T. M., Ringle, C. M., \& Sarstedt, M. (2017). A Primer on Partial Least Squares Structural Equation Modeling (PLS-SEM) (2nd Edition). Thousand Oaks: Sage Publications, Inc.

Horley, J., Carroll, B., \& Little, B. R. (1988). A Typology of Lifestyles. Social Indicators Research. Springer. https://doi.org/10.2307/27520746

Hur, W.-M., Kyung Kim, H., \& Park, J. (2010). Food- and situation-specific lifestyle segmentation of kitchen appliance market. British Food Journal, $112(3)$, 294-305. https://doi.org/10.1108/0007070101102 9165.
Kim, D., Rao, R., \& Cho, B. (2000). Effects of Consumer Lifestyles on Purchasing Behavior on the Internet: A Conceptual Framework and Empirical Validation. ICIS 2000 Proceedings. Retrieved from https://aisel.aisnet.org/icis2000/76

Kotler, P., dan Armstrong, G. 2012, Principles of Marketing; 14th Edition. Prentice Hall, Jakarta.

Laudon, K., \& Traver, C. G. (2014). ECommerce 2014; 10th Edition. New Jersey: Pearson Education, Inc.

Lien, C.-H., Wen, M.-J., Huang, L.-C., \& Wu, K.-L. (2015). Online hotel booking: The effects of brand image, price, trust and value on purchase intentions. Asia Pacific Management Review, 20(4), 210-218. https://doi.org/10.1016/J.APMRV.2015. 03.005

Maharani, N., \& Sevriana, L. (2017). Analysis of Attitude, Motivation, Knowledge and Lifestyle of the Consumers in Bandung Who Shop through Instagram. The Winners, 18(1), 13.

https://doi.org/10.21512/tw.v18i1.4049

Mohamed, N., Hussein, R., Hidayah Ahmad Zamzuri, N., \& Haghshenas, H. (2014). Insights into individual's online shopping continuance intention. Industrial Management \& Data Systems, 114(9), 1453-1476. https://doi.org/10.1108/IMDS-07-20140201.

Mohiuddin, Z. A. (2018). Effect of Lifestyle on Consumer Decision Making: A Study of Women Consumer of Pakistan. Journal of Accounting, Business and Finance Research, 2(1), 12-15. https://doi.org/10.20448/2002.21.12.15.

Plummer, J. T. (1974). The Concept and Application of Life Style Segmentation. Journal of Marketing, 38(1), 33. https://doi.org/10.2307/1250164 


\section{JURNAL ILMIAH MANAJEMEN DAN BISNIS

Rigdon, E. E., Sarstedt, M., \& Ringle, C. M. (2017). On Comparing Results from CB-SEM and PLS-SEM: Five Perspectives and Five Recommendations. Marketing ZFP, 39(3), 4-16. https://doi.org/10.15358/0344-13692017-3-4

Sekaran, U., \& Bougie, R. (2017). Metode Penelitian untuk Bisnis (Edisi 1). Jakarta: Salemba Empat.

To, P.-L., Liao, C., \& Lin, T.-H. (2007). Shopping motivations on Internet: A study based on utilitarian and hedonic value. Technovation, 27(12), 774-787. https://doi.org/10.1016/J.TECHNOVA TION.2007.01.001.

Turban, E., King, D., Lee, J. K., Liang, T.-P., \& Turban, D. C. (2015). Electronic Commerce. Cham: Springer International Publishing. https://doi.org/10.1007/978-3-31910091-3.

Warayuanti, W., \& Suyanto, A. (2015). The Influence of Lifestyles and Consumers Attitudes on Product Purchasing Decision via Online Shopping in Indonesia. European Journal of Business and Management Www.Iiste.Org ISSN, 7(8), 74-80.

$\mathrm{Xu}$, Y., \& Huang, J.-S. (2014). Effects of Price Discounts and Bonus Packs on Online Impulse Buying. Social Behavior and Personality: An International Journal, 42(8), 12931302.

https://doi.org/10.2224/sbp.2014.42.8.1 293.

Zikmund, W. (2013). Business Research Methods (9th Ed.). Mason: OH: SouthWestern College Publishing. 